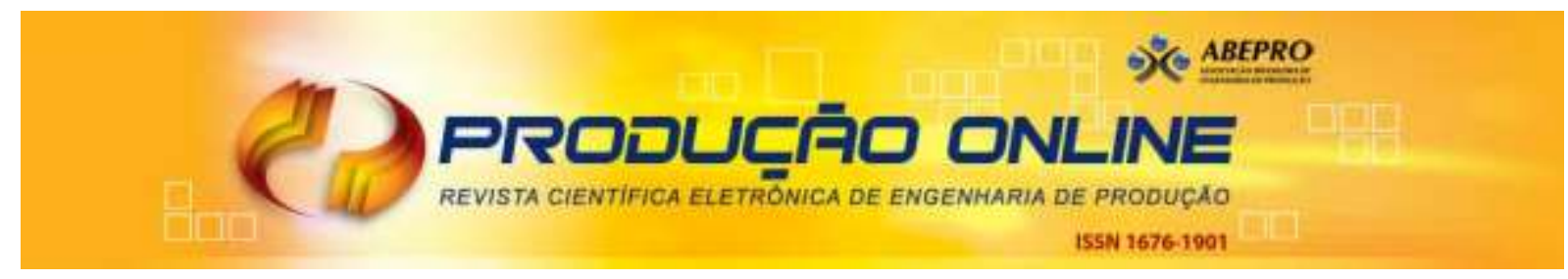

\title{
LEAN OFFICE E BPM: PROPOSIÇÃO E APLICAÇÃO DE MÉTODO PARA A REDUÇÃO DE DESPERDÍCIOS EM ÁREAS ADMINISTRATIVAS
}

\section{LEAN OFFICE AND BPM: METHOD PROPOSITION AND APPLICATION FOR REDUCING WASTE ON ADMINISTRATIVE AREAS}

\author{
Mateus Girardi Tegner* E-mail: mateustegner@hotmail.com \\ Pedro Nascimento de Lima* E-mail: pedrolima.n@gmail.com \\ Douglas Rafael Veit* E-mail: douglasveit@unisinos.br \\ Secundino Luis Henrique Corcini Neto* E-mail: secundino.corcini@hotmail.com \\ *Universidade do Vale do Rio dos Sinos (UNISINOS), São Leopoldo, RS
}

Resumo: A necessidade de eliminar desperdícios em áreas administrativas amplifica-se à medida que aumenta a competitividade nos setores, pressionando assim a redução de custos e despesas fixas. Neste contexto, além de mostrarem-se relevantes para as operações diretas, os conceitos e ferramentas Lean também ganham importância no escritório e em áreas de apoio. Apesar disto, os métodos disponíveis para a utilização do Lean em áreas administrativas carecem de integração com técnicas consolidadas pela literatura em Gerenciamento de Processos de Negócio. Frente a necessidade das organizações em eliminar desperdícios, e às lacunas identificadas na literatura existente sobre Lean Office, o presente artigo apresenta a proposição de um método para a implantação do Lean em áreas administrativas, incorporando o uso de técnicas de Gerenciamento de Processos. Além disto, este trabalho apresenta a aplicação do método no Sindicato das Indústrias Metalúrgica, Mecânica e de Material Elétrico e Eletrônico de São Leopoldo - SINDIMETAL. Para este objetivo, o trabalho revisa os conceitos Lean e de Gerenciamento de Processos de Negócio, utilizando como método de pesquisa a Design Science Research. Por fim são discutidas implicações a partir destas proposições bem como perspectivas para o desenvolvimento do Lean como alternativa para melhoria em operações administrativas.

Palavras-chave: Lean office. Lean. Gerenciamento de processos. Processos. Implementação do lean office.

\begin{abstract}
The need to reduce waste in administrative areas is amplified by the increasing competitiveness in all sectors, inducing the need to minimize costs and fixed expenses. Given such cost reduction imperative, Lean concepts are in demand not only at the manufacturing shop-floor, but also at the office. Nevertheless, the available methods to use Lean in administrative areas are not integrated with the already consolidated techniques tailored by the Business Process Management literature. Considering this context, this article aims to propose a method for using Lean concepts and tools in administrative areas, making use of Business Process Management techniques. In addition, this paper presents an application of the proposed method at the São Leopoldo Syndicate of Metallurgical, Mechanical, Electrical and Eletronic Manufacturers - SINDIMETAL. A Design Science approach is used to the method's proposal, which is based on Lean and Business Process Management concepts. The method is explained and its steps are tested with a real-world application. Finally, theoretical implications are discussed based on the experience with the proposed method, and further research is suggested for the development of Lean as an alternative for administrative operations improvement.
\end{abstract}

Keywords: Lean office. Business process management. Lean office implementation. 


\section{INTRODUÇÃO}

É consenso estabelecido que todas as empresas devem minimizar seus custos fixos e despesas. Em momentos de estagnação econômica, como a que o Brasil atualmente atravessa (EXAME, 2015), a redução ou contenção de custos fixos e despesas é imperativa. Empresas que sabem operar com baixos custos fixos e despesas serão mais resistentes às intempéries econômicas do que aquelas com altos custos fixos e despesas. As áreas administrativas que geram custo fixo indireto, como os setores de PCP e Manutenção, bem como as que geram despesas (Financeiro, Compras, etc), sempre serão pressionadas a manter suas entregas em função do menor custo possível. Isto faz com que haja pressão para a não contratação de mão-de-obra adicional em tais áreas. Desta maneira, surge a necessidade de manter o escritório enxuto.

A partir desta necessidade, os conceitos do Sistema de Produção Enxuta foram aplicados às áreas administrativas, e seus resultados foram relatados repetidamente por diversos acadêmicos ((TURATI; MUSETTI, 2006); (BARBALHO; RICHTER; ROZENFELD, 2007); (ROOS; SARTORI; PALADINI, 2001); (CARDOSO; SOUZA; ALVES, 2012)). Tapping e Shuker (2010) avançaram para além da aplicação isolada de ferramentas Lean no ambiente dos escritórios, propondo um método embasado na aplicação da ferramenta VSM (Value Stream Management). Sua obra, intitulada "Oito Passos Para Planejar, Mapear e Sustentar Melhorias Lean em áreas administrativas" organiza algumas ferramentas Lean em torno do VSM, anteriormente proposto por Rother e Shook (2003). Ao redor deste método, Tapping e Shuker (2010) sugerem a aplicação de outras ferramentas Lean, como o Trabalho padronizado, Heijunka, 5S's, Kanban, entre outras. A publicação deste livro contribuiu estruturando o primeiro método dedicado à aplicação do Lean em áreas administrativas (também chamado de Lean Office).

Uma série de publicações relataram a aplicação total ou parcial dos passos sugeridos por Tapping e Shuker (2010) (BARBALHO; RICHTER; ROZENFELD, 2007; CARDOSO; SOUZA; ALVES, 2012). Tais trabalhos contribuem à literatura existente como indícios que mostram os resultados que os conceitos Lean têm a oferecer, porém carecem de críticas e contribuições teóricas que avancem em relação ao método proposto por Tapping e Shuker (2010). Reconhecendo a necessidade de prover ferramentas para a identificação de perdas em processos de negócio (por eles chamadas de áreas indiretas), Magenheimer, Reinhart e Schutte (2014) propõem uma abordagem para a identificação e quantificação das perdas. Por mais que esta abordagem possua uma etapa intitulada "Modelagem do Processo", esta termina na quantificação do impacto que as perdas identificadas têm sobre as necessidades do cliente, não avançando para a proposição de um novo processo. Além disto, a abordagem utilizada para o mapeamento do processo atual utiliza como base o VSM, que carece de detalhamento em nível de atividade. Por fim, Magenheimer, Reinhart e Schutte (2014) sugerem como trabalhos futuros o desenvolvimento de um método ou uma coleção de abordagens adaptadas e uma ordem de implementação para a 
eliminação de perdas de um modo sustentável, ressaltando que as abordagens atuais focam somente em melhorar pontos isolados, sem concentrar-se em todo o fluxo de valor. Como será discutido adiante, este é um dos gaps abordados por este trabalho.

Em nível nacional, Greef, Freitas e Romanel (2012) contribuem com a disseminação do Lean Office por meio da publicação do livro Lean Office, porém a obra carece de um método conciso para a aplicação dos conceitos expostos. Em busca às bases de Periódicos da ABEPRO, contendo: i) Revista Produção Online; ii) Revista Produção; e iii) Brazilian Journal of Operations \& Production Management (BJO\&PM), nenhuma publicação com o termo lean office é encontrada. Visitando as publicações do Encontro Nacional de Engenharia de Produção nos últimos 10 anos, 12 trabalhos abordam o tema lean office. Consultando a livraria eletrônica SciELO, é localizado um único trabalho, tratando sobre Lean Office em organizações militares de saúde (SERAPHIM; SILVA; AGOSTINHO, 2010). Analisando o Portal de Periódicos CAPES, a busca por lean office no título de trabalhos em publicados no Brasil traz a colaboração de um trabalho tratando o conceito de Lean Office aplicado a um ambiente industrial com produção tipo Engineer to Order (DE PAOLI; ANDRADE; LUCATO, 2014). A Tabela 1 resume os resultados da revisão literária em lean office no Brasil.

Tabela 1 - Resumo da revisão literária em lean office no Brasil

\begin{tabular}{|c|c|c|c|}
\hline $\begin{array}{l}\text { Termos de } \\
\text { busca }\end{array}$ & Base de Dados & $\begin{array}{c}\text { Publicações } \\
\text { encontradas }^{* *}\end{array}$ & $\begin{array}{c}\text { Integração com } \\
\text { EPN/GPN }\end{array}$ \\
\hline \multirow{6}{*}{ Lean Office } & Revista Produção Online & 0 & 0 \\
\hline & Revista Produção & 0 & 0 \\
\hline & BJO\&PM & 0 & 0 \\
\hline & ENEGEP (2006 a 2015) & 12 & 0 \\
\hline & SciELO Brasil & 1 & 0 \\
\hline & Portal Capes & 1 & 0 \\
\hline & TOTAL & 14 & 0 \\
\hline
\end{tabular}

Fonte: Elaborada pelos Autores (2016)

Em uma análise quantitativa, o baixo número de trabalhos acadêmicos sobre 0 tema demonstra a necessidade de evolução desta vertente do Lean Manufacturing no Brasil. Analisando qualitativamente, há uma ausência de diálogo entre a literatura e os métodos que tratam de Lean Office e a literatura existente em Engenharia de Processos de Negócio e Gerenciamento de Processos de Negócio (também conhecido por BPM - Business Process Management), justificando a elaboração deste trabalho. Tapping e Shuker (2010) utilizam como técnica de mapeamento apenas o VSM, enquanto existem outros métodos utilizados mundialmente no mapeamento de processos de negócio (ex.: BPMn, Architecture of Integrated Information System - ARIS). 
Contrapondo com os números atuais no país, a base de dados EBSCOhost traz 184 publicações sobre lean office, através de uma busca aberta. O Google Scholar levanta 200 trabalhos com lean office no título. A base de dados ScienceDirect entrega 40 obras e a Scopus 284 materiais com o termo lean office no título, resumo e palavras-chave. Essa comparação demonstra a relevância do tema de maneira global e a falta de trabalhos nacionais neste tema. A Tabela 2 resume a revisão literária em lean office nas bases internacionais.

Tabela 2 - Resumo das revisões literárias em lean office nas bases internacionais

\begin{tabular}{clr}
\hline Termos de busca & Base de Dados Publicações encontradas \\
& EBSCOhost & 184 \\
Lean Office & Google Scholar & 200 \\
& ScienceDirect & 40 \\
& Scopus & 283 \\
& & 717
\end{tabular}

Fonte: Elaborada pelos Autores (2016)

Evidenciadas as limitações atuais da literatura em Lean Office, este trabalho propõe responder à seguinte questão de pesquisa: "Como deve ser um método que permita implantar o Lean Office em uma área administrativa, incorporando técnicas de Gerenciamento de Processos de Negócio? ". Partindo desta questão, define-se como objetivo geral deste trabalho a proposição de um método para a implantação do Lean em áreas administrativas, incorporando técnicas de Gerenciamento de Processos de Negócio.

Para alcançar este objetivo, uma revisão dos pilares teóricos do Lean, seus desdobramentos para áreas administrativas e Gerenciamento de Processos de Negócio foi conduzida. Em seguida é evidenciada a metodologia de pesquisa e o método de trabalho utilizado no desenvolvimento desta obra. $O$ trabalho segue apresentando e detalhando as etapas do método proposto, avaliando a integração entre o Lean Office e Gerenciamento de Processos de Negócio. É também apresentada uma aplicação do método proposto no Sindicato das Indústrias Metalúrgica, Mecânica e de Material Elétrico e Eletrônico de São Leopoldo SINDIMETAL e, ao fim, são discutidas as implicações deste trabalho e as aprendizagens obtidas na sua aplicação.

\section{REFERENCIAL TEÓRICO}

Para a proposição de um método que preencha as lacunas identificadas na introdução deste trabalho é necessário, além de discutir o método proposto por Tapping e Shuker (2010), voltar às origens do próprio sistema de produção enxuta. Isto faz-se necessário considerando que o método proposto por tais autores tem como ponto de partida a ferramenta VSM. 


\subsection{Origem e definição do lean}

O Sistema Toyota de Produção (STP), apresentado por Shingo (1996), pode ser entendido como um sistema que visa a eliminação total das perdas, ou seja, uma rede funcional de operações e processos, que pode ser uma fábrica ou um escritório, com o objetivo claro da eliminação das atividades que geram custo e que não agregam valor sob o ponto de vista do cliente. As perdas, amplamente difundidas na literatura, são definidas tradicionalmente por sete, sendo: i) defeitos; ii) superprodução; iii) esperas; iv) transporte; v) processamento em si; vi) estoque; vii) movimentação. Além das 7 perdas, Shingo (1996) expressa dois tipos de perdas genéricas na manufatura: i) mura: falta de regularidade na operacionalização da produção, levando a alta variabilidade; ii) muri: sobrecarga nas pessoas ou equipamentos, levando ao desgaste precoce devido ao ritmo acelerado.

A denominação de STP para o termo Produção Enxuta (Lean Manufacturing) fora trazido por Womack, Jones e Roos (1990), no qual os pesquisadores do Massachussets Institute of Technology (MIT) relatam uma pesquisa em mais de 90 instalações de diversas empresas da indústria automobilística em 17 países, explicitando o pensamento e técnicas da produção enxuta presentes em tais organizações.

\subsection{Lean office - práticas lean em áreas administrativas}

Os conceitos do Lean, apesar de terem sido criados e inicialmente introduzidos à manufatura, estão sendo estudados e aplicados em diversas áreas ao longo dos anos, podendo-se destacar: construção civil, tecnologia da informação, recursos humanos, educação, serviço público e às áreas administrativas, que é foco deste trabalho. A obra seminal referente ao tema é escrita por Tapping e Shuker (2010), na qual apresenta-se uma metodologia para planejar, mapear e sustentar as melhorias do Lean através da coleta e análise sistemática de dados. A publicação trata do VSM em oito etapas, que correspondem:

a) Comprometer-se com o Lean: alinhamento entre a gerência, administração e os funcionários quanto a seus esforços contínuos com as iniciativas Lean, bem como a definição da equipe de implementação;

b) Escolher o Fluxo de valor: definição de todas as atividades, incluindo as que não agregam valor, que fazem a transformação de informações e matéria-prima em um produto final que o cliente se dispõe a pagar;

c) Aprender sobre Lean: revisão dos conceitos e ferramentas Lean que devem ser transmitidos aos envolvidos durante $o$ treinamento;

d) Mapear o Estado Atual: expressão do fluxo do objeto do trabalho e informações por meio de uma representação visual;

e) Identificar as Métricas Lean: determinação das métricas que ajudarão a alcançar as metas Lean da empresa, utilizando-as para auxiliar a conduzir a melhoria contínua e eliminação de desperdício; 
f) Mapear o Estado Futuro: entendimento das demandas do cliente, estabelecendo um fluxo contínuo para que os clientes internos e externos recebam o objeto do trabalho correto, no momento e quantidade correta, distribuindo o trabalho uniformemente;

g) Criar os Planos Kaizen: criação dos planos Kaizen para modificar e melhorar os processos estudados, também como o planejamento das fases de implementação dos Kaizen;

h) Implementar os Planos Kaizen: momento de executar a transformação Lean, implementando as atividades Kaizen previamente planejadas.

Diversos trabalhos foram publicados no Brasil trazendo aplicações da abordagem proposta por Tapping e Shuker (2010). Dentre eles, destacam-se: Turati e Musetti (2006), demonstrando aplicações no setor administrativo público; Barbalho, Ritchter e Rozenfeld (2007) que propõem melhorias no processo de aquisição de materiais para prototipagem de produtos; Roos, Sartori e Paladini (2011), que relatam uma aplicação passo a passo com objetivo da redução e eliminação de desperdícios no fluxo de valor de informações e conhecimentos em uma empresa prestadora de serviços; Rocha e Walter (2015), identificando possibilidade de melhorias no fluxo de trabalho de uma empresa prestadora de serviços de tecnologia da informação.

No estudo de Oliveira (2007), evidencia-se que em áreas administrativas são predominantes as atividades de geração de informação e, sendo este um produto intangível, a dificuldade de visualizar o caminho a qual o produto percorre, do pedido à entrega, é maior que em ambientes fabris, onde os produtos são tangíveis. Greef, Freitas e Romanel (2012) propõem que para melhor identificação do fluxo de informação sejam aplicados os conceitos de Gestão da Informação em todos os processos e que, para um ambiente seja denominado um Lean Office, devem ser atribuídos aos seus processos características da mentalidade enxuta.

\subsection{Gerenciamento de Processos}

Segundo Zairi (1997), Business Process Management (BPM) é uma abordagem estruturada para analisar e melhorar continuamente atividades fundamentais das empresas como fabricação, marketing, comunicações e outros grandes elementos que fazem parte da operação de uma empresa. Lee e Dale (1998) trazem um estudo onde BPM é interpretado como a mensuração dos principais processos, análise do que funciona e o que não funciona e melhorá-los. Em poucas palavras, entende-se a gestão por BPM como eliminação de desperdício e agregação de valor nos processos. Esta afirmação demonstra claramente a convergência entre os objetivos do Lean e do BPM.

Paim (2002) propõe que os projetos de ações de Engenharia de Processos devem ser realizados em 4 etapas, que são entendidas por:

a) Preparação: definição do objetivo do projeto, o nivelamento dos participantes do projeto conceitualmente, a difusão do projeto e seus resultados, a definição de 
um macroprocesso para servir de referência, a definição dos entrevistados e do cronograma;

b) Desenvolvimento: descrição dos processos existentes, identificação de problemas, análise e propostas de melhorias, visando a geração de novos desenhos para os processos. O fim desta etapa ocorre com a validação dos novos processos;

c) Implantação: planejamento da implementação que deve ser feita no futuro. Esta etapa pode ser entendida pela definição de o que deve ser feito para que os processos redesenhados sejam executados;

d) Implementação: execução, controle e acompanhamento dos novos processos.

A seção seguinte demonstra o método de pesquisa e o método de trabalho utilizado no desenvolvimento desta obra.

\section{MÉTODO DE PESQUISA}

Quando realizada sob o paradigma das ciências tradicionais e sociais, a pesquisa almeja explicar, descrever, explorar ou predizer fenômenos. Em trabalhos que tem como objetivo a proposição de artefatos (como métodos e modelos) ou prescrições, as metodologias usadas nas ciências tradicionais podem apresentar limitações. Neste contexto, surge a Design Science, como um novo paradigma para a condução de pesquisas, e a Design Science Research, como método que operacionaliza a pesquisa (DRESCH; LACERDA; ANTUNES, 2015; LACERDA et al., 2013). Considerando que o objetivo da pesquisa define o método de pesquisa a ser utilizado, bem como considerando a Design Science Research como mais adequada que o Estudo de Caso ou Pesquisa-Ação (DRESCH; LACERDA; ANTUNES, 2015) para a prescrição de um método, define-se a Design Science Research como o método de pesquisa deste trabalho sob a justificativa de permitir a proposição de um método que resulte em soluções satisfatórias ou melhores que as atuais para determinado problema prático. A partir do método proposto por estes autores, definem-se os passos a seguir como método de trabalho desta pesquisa:

a) Conscientização do Problema: Identificação dos conceitos e métodos em relação a Lean Manufacturing e Engenharia de Processos de Negócio;

b) Identificação dos Artefatos: Identificação dos métodos existentes para a implantação do Lean Office, bem como de suas lacunas;

c) Desenvolvimento do Artefato: Proposição do Método para implantação do Lean Office baseado nos conceitos Lean e ferramentas da Engenharia de Processos de Negócio;

d) Avaliação do Artefato: Aplicação do Método proposto no Sindicato das Indústrias Metalúrgica, Mecânica e de Material Elétrico e Eletrônico de São Leopoldo - SINDIMETAL e avaliação do mesmo;

e) Explicitação das Aprendizagens: Formalização das aprendizagens desenvolvidas ao longo do processo de construção do artefato; 
f) Conclusões: Demonstração dos resultados gerados a partir do desenvolvimento e aplicação do artefato, exibida através deste artigo;

g) Generalização para uma classe de problemas: Proposta do método genérico podendo ser aplicado em projetos aplicados à diferentes ramos de negócio;

h) Comunicação dos resultados: Divulgação da proposta e aplicação à academia. A execução dos passos do método de trabalho é explicitada neste trabalho conforme indicado a seguir. Os passos a e b foram explicitados na introdução e referencial teórico deste trabalho. O passo c é explicitado na seção 4 deste trabalho, e o passo d, na seção 5 . Os passos e, f e g são explicitados na seção 6 , e este trabalho como um todo representa o passo $\mathrm{h}$.

\section{PROPOSIÇÃO DE MÉTODO PARA A IMPLANTAÇÃO DO LEAN OFFICE}

Esta seção dedica-se à descrição do método proposto para a implantação do Lean Office em áreas administrativas. A Figura 1 ilustra as etapas do Método discutidas a seguir.

Considerando que um fator de sucesso para a utilização de um método como este é a definição das pessoas a serem envolvidas, faz-se necessário mobilizar os recursos necessários e adequados, explicitando os papéis que devem ser assumidos para a condução das iniciativas de implantação do Lean Office. No primeiro papel, o Sponsor é aquele que detém a autoridade de mobilização dos envolvidos no processo, usualmente um diretor ou gerente na organização. Em havendo o comprometimento do Sponsor, é importante que se defina o "Dono do Processo".

$O$ dono do processo trabalha na gestão do fluxo de valor a ser mapeado, e deve estar presente durante as etapas do projeto, tendo a responsabilidade de gerir o processo de implantação do Lean, no fluxo de valor definido. Recomenda-se que as iniciativas não sejam declaradas como iniciadas caso o Sponsor e o Dono do Processo não estejam dispostos a destinar tempo e recursos humanos para a sua condução.

Para a condução das atividades do projeto, é necessária a formação de uma Equipe Facilitadora. $O$ dono do processo deve mobilizar uma Equipe Interna Facilitadora, que faz parte da organização em questão e executará as principais atividades do processo. Quando a Equipe Interna Facilitadora ainda não possui as competências e/ou tempo disponível necessário para a condução completa das atividades, pode ser necessária a ajuda de uma Equipe Consultora para a formação da Equipe Facilitadora, bem como para acompanhamento técnico durante a construção para que a iniciativa de lean office seja bem planejada e executada. Tal equipe pode contribuir por possuir imparcialidade quanto ao tema em questão, bem como prover uma visão externa sobre o caso.

Em seguida, é necessário Capacitar a Equipe Facilitadora, já que o grupo de pessoas a conduzir os trabalhos pode apresentar um desnivelamento ou ausência de consenso sobre os conceitos Lean, bem como pouca ou nenhuma experiência no uso de técnicas de modelagem de gerenciamento de processos necessárias nos passos posteriores do método. Ainda que sejam utilizados recursos humanos externos 
durante as demais etapas, é importante que a equipe interna à empresa seja capacitada, considerando o objetivo de internalizar as competências necessárias para a implantação do Lean, fazendo com que futuramente a organização realize as práticas de lean office sem o auxílio externo.

Figura 1 - Método para Implantação do Lean Office

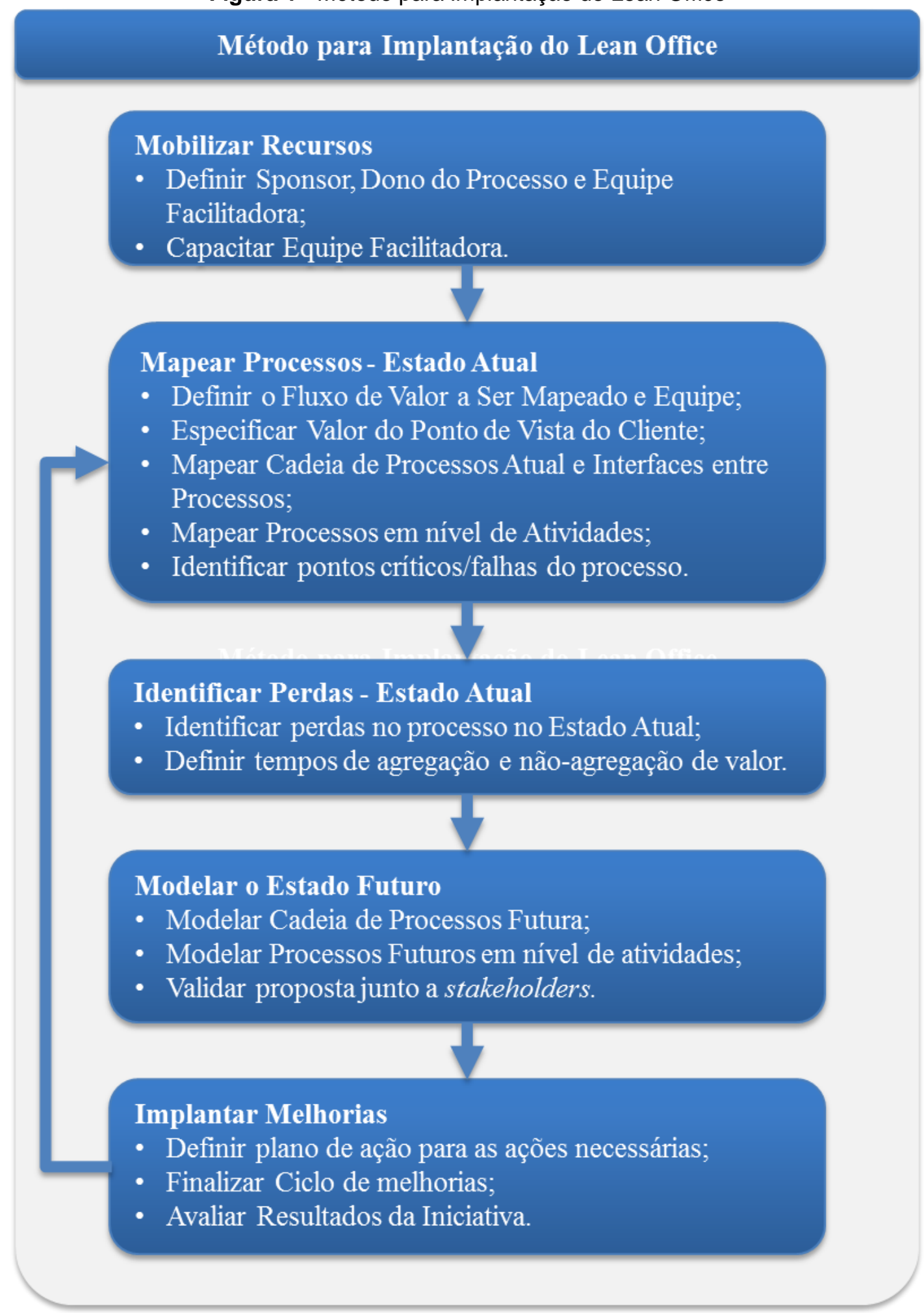

Fonte: Elaborada pelos Autores (2016)

Revista Produção Online, Florianópolis, SC, v. 16, n. 3, p. 1007-1032, jul./set. 2016. 
Estando a equipe capacitada, inicia-se a macro etapa "Mapear Processos Estado Atual", que começa pela etapa "Definir o Fluxo de Valor a Ser Mapeado e Equipe". O fluxo de valor a ser mapeado compreende os processos para a produção de uma família de produtos ou serviços. Visto que o método pode ser executado em diversos ciclos, pode ser necessário reformular a equipe facilitadora e, por este motivo, a formação da equipe deve ser revista em função do fluxo de valor estudado. Em seguida deve-se "Especificar Valor do Ponto de Vista do Cliente". Nesta etapa deve ser respondida a pergunta: "O que este processo entrega ao cliente? ". Dado que a metodologia tradicional do VSM traz como pressuposto a importância do lead time (o que, em algumas situações particulares é valido, mas não em todas), e em ambientes administrativos o lead time pode não ser um fator crítico, é necessário redefinir, baseado na realidade em questão, o que significa agregação de valor na situação específica.

Em seguida, é necessário “Mapear Cadeia de Processo Atual e Interfaces Entre Processos". Nesta etapa, pode ser utilizada a notação do VSM, demonstrando quais são os processos que compõem o fluxo de valor e como são as relações entre estes processos. É também importante que sejam delimitadas as fronteiras dos processos mapeados, evitando lacunas e sobreposições durante o mapeamento, bem como para que sejam esclarecidas dúvidas em termos de nomenclatura. Para a definição destes limites, é adequado que seja estabelecido quais são os fornecedores, entradas, saídas e clientes de cada um dos processos mapeados. Isto pode ser feito utilizando-se a ferramenta SIPOC.

Após a condução do mapeamento da cadeia de processos atual e interfaces, será possível “Mapear Processos em nível de Atividades". Deste modo, cada uma das etapas de agregação de valor descritas no VSM será "explodida" permitindo a visualização de atividades que fazem parte da mesma. Considerando que em processos administrativos é frequente a ocorrência de loops de decisão, é necessária uma notação que permita a visualização dos diferentes atores envolvidos em cada um dos processos, bem como que permita a visualização do fluxo de informação. Para esta etapa, recomenda-se o uso do EPC (Event Driven Process Chain) como forma de modelagem. Outras técnicas e notações também podem ser utilizadas, como o BPMn (Business Process Management Notation). Independentemente da notação utilizada para a modelagem, este mapeamento deve ser feito por meio de entrevistas/reuniões junto aos executores do processo, para que estes informem como as coisas acontecem na prática, sendo possível gerar melhorias factíveis com a realidade da organização. É comum que se faça reuniões de validação dos resultados do mapeamento com o Dono do Processo para que o estado atual seja um consenso entre os envolvidos. Finalizando esta macro etapa, resta "Identificar pontos críticos/falhas do processo". Durante o mapeamento dos processos em nível de atividades no estado atual é importante que sejam levantados os pontos críticos ou falhas no processo atual, visto que os mesmos naturalmente são evidenciados durante o mapeamento do processo em nível de atividade. Após esta etapa parte-se para a etapa "Identificar Perdas - Estado Atual”. Utilizando a 
classificação de trabalho (Perda, Trabalho Adicional e Trabalho Efetivo), é possível distinguir as atividades que não agregam valor e não são necessárias, as que não agregam valor e são necessárias, bem como as que agregam valor ao cliente, além mapear, se possível for, os tempos de agregação e não-agregação de valor.

Identificados os pontos de falha e perdas, segue-se a etapa "Modelar o Estado Futuro". Nesta etapa deve-se Modelar a Cadeia de Processos Futura e os processos em nível de atividade. Desta maneira, utilizando a mesma notação do estado atual e os pontos de falha identificados, se projeta o funcionamento do sistema futuro. Neste ponto do método é fundamental a participação ativa dos envolvidos no processo, para que o processo projetado logre sucesso. Finalmente, deve-se validar esta proposta junto aos stakeholders (tanto participantes do processo quanto o sponsor do projeto) e, se necessário, seja revisado até a validação.

Ao fim, dado que há um consenso sobre o estado futuro do projeto, deve-se conduzir a etapa "Implantar Melhorias". Sugere-se a utilização de planos de ação para a formalização e controle das ações necessárias. Para cada ação, há um responsável pela sua operacionalização, e também deve ser feito o acompanhamento da mesma, se possível pelo Dono do Processo. Uma vez que as ações previstas nestes planos de ação tenham sido implantadas, é importante conduzir a etapa "Finalizar Ciclo de Melhorias". Este marco define o fim do prazo estipulado para que se efetue as melhorias no macroprocesso. Porém, se uma boa ideia não pode ser executada durante 0 prazo, esta não deve ser descartada, e sim reavaliada e recolocada em pauta para que se concretize. Por fim, recomenda-se "Avaliar Resultados da Iniciativa", visando identificar fatores a serem repetidos ou não em uma próxima iniciativa semelhante, bem como quais ações tiveram seu objetivo atingido, parcialmente atingido ou não atingiram suas metas iniciais. A Figura 2 explicita os pontos nos quais observa-se a integração entre as contribuições da literatura existentes sobre Lean Manufacturing e a Engenharia de Processos de Negócio, em relação à cada uma das etapas do método proposto. Tais contribuições integram a definição do método proposto e descrito acima. 
Figura 2 - Análise do Método Proposto para Implantação do Lean Office

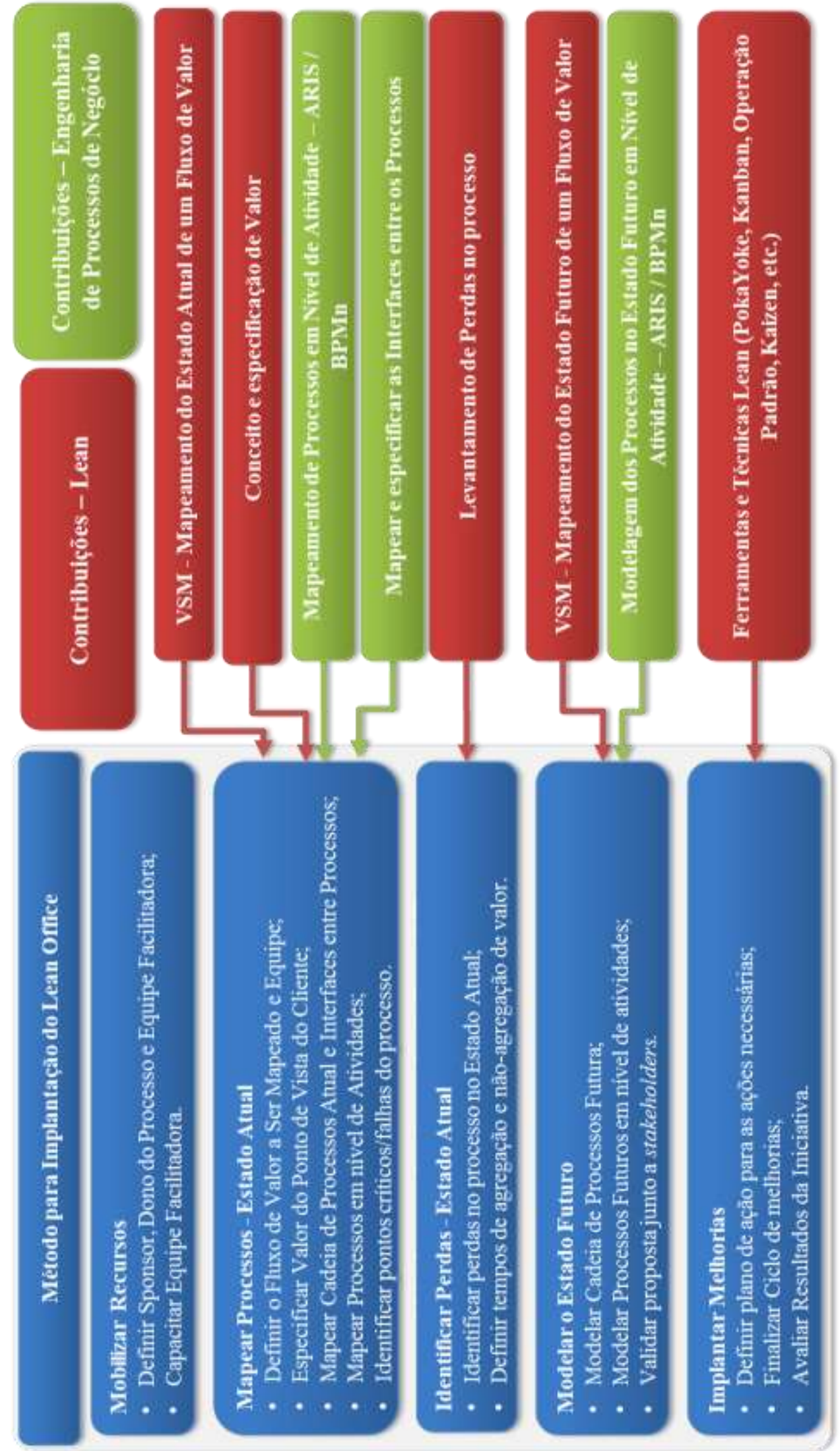

Fonte: Elaborada pelos Autores (2016)

Revista Produção Online, Florianópolis, SC, v. 16, n. 3, p. 1007-1032, jul./set. 2016. 


\section{APLICAÇÃO DO MÉTODO}

Esta seção apresenta a aplicação do método no Sindicato das Indústrias Metalúrgicas, Mecânica e de Material Elétrico e Eletrônico de São Leopoldo (SINDIMETAL). A entidade sindical atua nos moldes atuais desde 1956 e cobre um total de 35 municípios do estado do Rio Grande do Sul, tendo mais de 1500 empresas filiadas e mais de 160 associadas, representando um total de 38 segmentos. O SINDIMETAL presta serviços aos associados/filiados no que tange à cursos, encontros de negócios, exposições, fóruns, meetings, visitas técnicas e missões empresariais, assessorias diversas e outros benefícios. Baseado na revisão da literatura e conhecimento de outros sindicatos, pode-se afirmar que o SINDIMETAL é o primeiro sindicato a atuar com iniciativas de lean office no Brasil.

O método foi aplicado no fluxo de valor de Qualificação, de fevereiro a dezembro de 2015, percorrendo as etapas definidas acima no método. No primeiro momento, foram definidos os recursos humanos que acompanharam o andamento do projeto, do início ao fim. Estiveram alocados neste caso 3 especialistas lean para participar no acompanhamento de todo o processo, sendo definida e a equipe consultora. Antes do início da iniciativa de lean office, já estava definida a equipe facilitadora, e esta foi apenas formalizada para receber capacitações em termos de conceitos, métricas e ferramentas Lean, também como em gerenciamento de processos. Esta decisão veio da necessidade de nivelar as pessoas envolvidas quanto ao conhecimento sobre o tema, dado que possuem diferentes tipos de formações, além de criar um vocabulário comum que facilite a comunicação. O objetivo destes treinamentos é que as equipes facilitadoras se tornem, em um futuro breve, as equipes consultoras, dando suporte no mapeamento e condução do método proposto em outras áreas.

Concluída a mobilização dos recursos, foi decidido o fluxo de valor a ser mapeado e trabalhado nesta instância do projeto. Considerando que esta foi a primeira aplicação do Lean Office no SINDIMETAL, foi escolhido um fluxo de valor que envolve um grande número de pessoas na organização, com o objetivo de facilitar a absorção dos conceitos e o envolvimento em tal iniciativa. Outros critérios, porém, podem ser usados em futuras situações, e são mais adequados, como os fluxos de valor mais críticos para o sucesso da empresa.

Definido o fluxo de valor a ser mapeado, foi conduzida uma discussão sobre a especificação do valor entregue pelo processo em questão sob o ponto de vista do cliente. Considerando que o público do processo selecionado são profissionais integrantes das empresas associadas e filiadas ao SINDIMETAL, foram destacados como especificadores a disseminação de conhecimento, a utilidade do conhecimento absorvido para a melhoria do negócio, e o retorno sobre o investimento. Além destes pontos, foi destacado que o processo de qualificação permite a visibilidade da empresa, bem como a promoção do networking entre os participantes. Tal discussão foi relevante para o entendimento e questionamento das atividades que são perdas, trabalho adicional e trabalho efetivo. Deste modo, tais fatores foram considerados ao 
longo do projeto para a definição de perdas e ações de melhoria. Em sequência à esta atividade, foi mapeada a cadeia de processos relacionados à qualificação no SINDIMETAL. Tal mapeamento foi realizado por meio de workshops com a participação dos principais envolvidos neste processo, culminando na organização ilustrada na Figura 3, a qual apresenta as ligações entre os processos e com as entidades envolvidas.

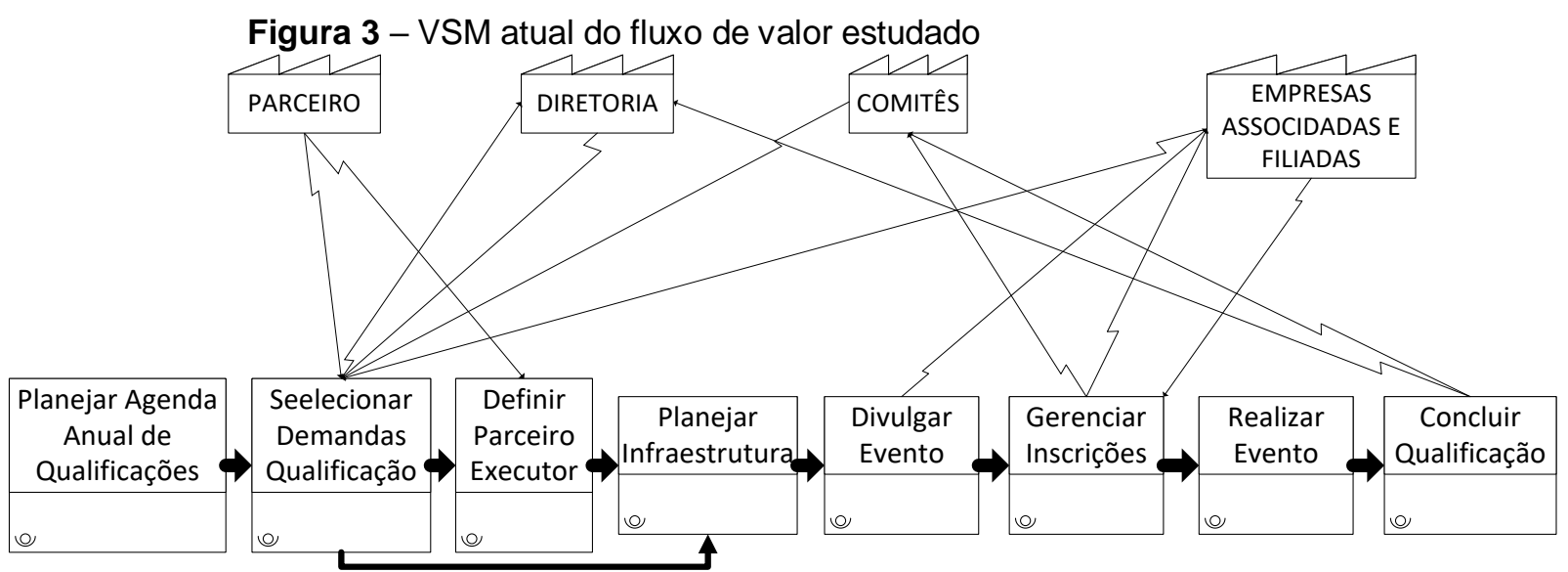

Fonte: Elaborada pelos Autores (2016)

Desenhado o fluxo de valor definido (Qualificação), foram definidas as fronteiras dos processos que o compõem, ou seja, quais são os eventos e entradas que levam ao início de cada um dos processos, bem como quais são os eventos e saídas que determinam a finalização de cada um dos processos. O Quadro 1 apresenta as entradas e saídas respectivas a cada um dos processos que compõem o fluxo de valor Qualificação. 
Quadro 1 - Entradas e saídas dos processos

\begin{tabular}{|c|c|c|}
\hline Entradas & Processo & Saídas \\
\hline $\begin{array}{l}\text { Demanda de qualificação } \\
\text { recebida; } \\
\text { Oferta de qualificação } \\
\text { recebida; } \\
\text { Histórico anual qualificação. }\end{array}$ & $\begin{array}{l}\text { Planejar Agenda Anual } \\
\text { de Qualificações }\end{array}$ & Plano anual de qualificação. \\
\hline $\begin{array}{l}\text { Demanda de qualificação } \\
\text { recebida; } \\
\text { Oferta de qualificação } \\
\text { recebida; } \\
\text { Planejamento anual } \\
\text { qualificação. }\end{array}$ & $\begin{array}{c}\text { Selecionar Demandas } \\
\text { Qualificação }\end{array}$ & $\begin{array}{l}\text { Escopo da qualificação } \\
\text { selecionado. }\end{array}$ \\
\hline $\begin{array}{l}\text { Escopo da qualificação } \\
\text { selecionado; } \\
\text { Lista de parceiros prioritários } \\
\text { definida. }\end{array}$ & Definir Parceiro Executor & Parceiro executor definido. \\
\hline $\begin{array}{l}\text { Parceiro executor definido; } \\
\text { Escopo da qualificação } \\
\text { selecionado; } \\
\text { Agenda de salas e atividades } \\
\text { definida. }\end{array}$ & Planejar Infraestrutura & Infraestrutura providenciada \\
\hline $\begin{array}{l}\text { Infraestrutura providenciada; } \\
\text { Público alvo e escopo. }\end{array}$ & Divulgar Evento & $\begin{array}{l}\text { Material divulgação } \\
\text { finalizado; } \\
\text { Divulgação realizada. }\end{array}$ \\
\hline $\begin{array}{l}\text { Divulgação iniciada; } \\
\text { Lista de confirmações; } \\
\text { Relatório empresas (SIGER- } \\
\text { Sistema). }\end{array}$ & Gerenciar Inscrições & $\begin{array}{l}\text { Confirmação evento; } \\
\text { Prorrogação evento; } \\
\text { Cancelamento evento. }\end{array}$ \\
\hline $\begin{array}{l}\text { Confirmação evento; } \\
\text { Lista de responsabilidades; } \\
\text { Infraestrutura confirmada; } \\
\text { Material para realização } \\
\text { evento. }\end{array}$ & Realizar Evento & $\begin{array}{l}\text { Evento realizado; } \\
\text { Pesquisa de satisfação. }\end{array}$ \\
\hline $\begin{array}{l}\text { Evento realizado; } \\
\text { Pesquisa de satisfação. }\end{array}$ & $\begin{array}{c}\text { Concluir processo de } \\
\text { Qualificação }\end{array}$ & $\begin{array}{l}\text { Pesquisa da satisfação } \\
\text { compilado; } \\
\text { Certificado; } \\
\text { Indicadores; } \\
\text { Registro no SIGER. }\end{array}$ \\
\hline
\end{tabular}

Fonte: Elaborado pelos autores (2016)

Com fluxo, fronteiras e valores definidos, iniciou-se o detalhamento dos processos em atividades, como é detalhado em forma de EPC. A Figura 4 representa o estado atual do processo nomeado Concluir Qualificação. 
Figura 4 - Processo Concluir Qualificação no estado atual

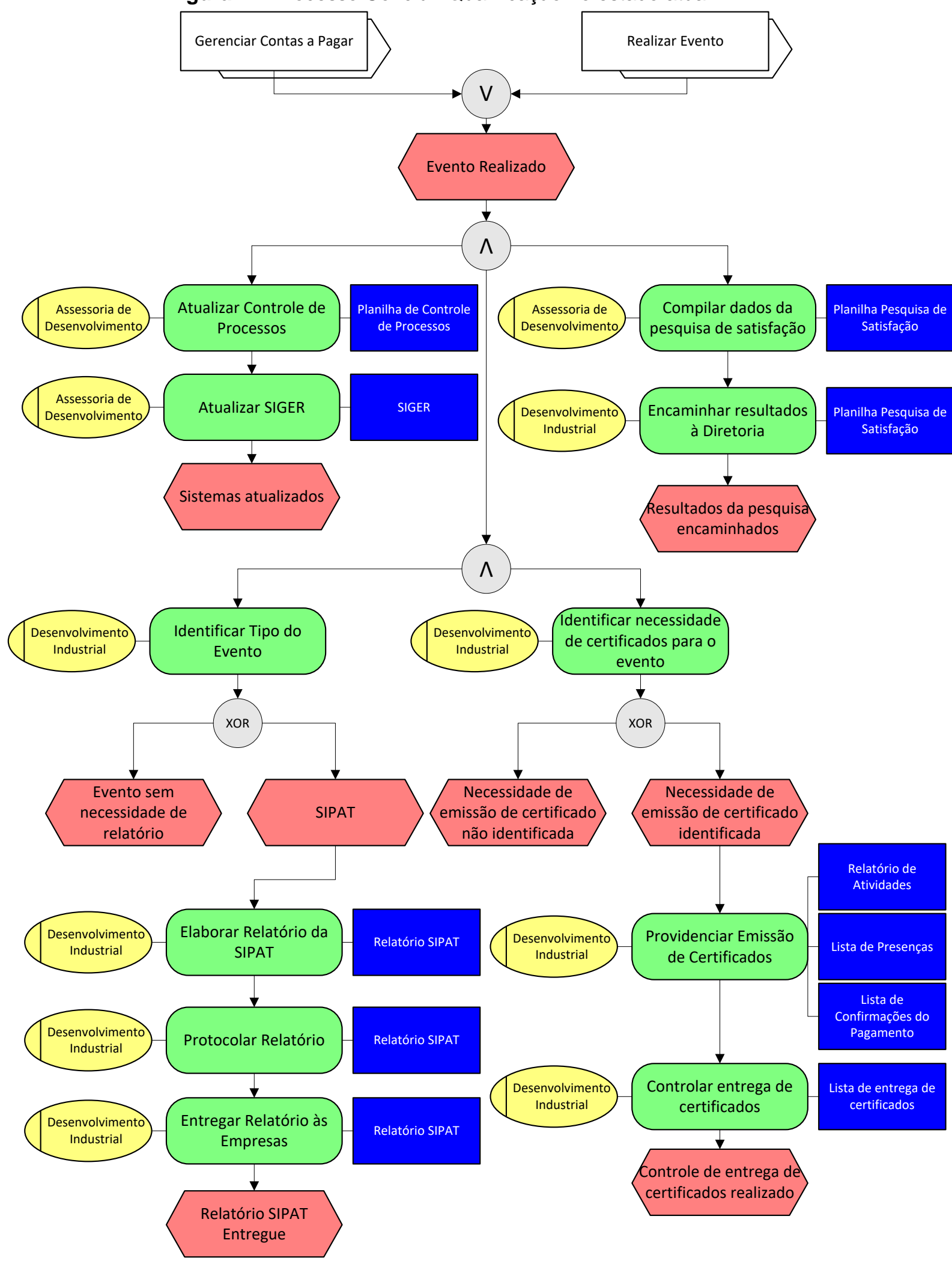

Fonte: Elaborado pelos Autores (2016)

Esta etapa do trabalho exigiu esforço de todos os envolvidos no processo, demonstrando ser uma etapa que explicita conflitos, que podem ser oriundos da não estruturação do processo atual.

Revista Produção Online, Florianópolis, SC, v. 16, n. 3, p. 1007-1032, jul./set. 2016. 
Diferente de um processo de manufatura que é visível, o mapeamento dos processos administrativos pode revelar ações sobrepostas, ou sem uma responsabilidade clara, como foi o caso em alguns processos mapeados neste caso

Junto a este passo, os executores dos processos devem ser questionados para que expressem quais são os pontos de falha que encontram no dia-a-dia, os quais servem como input para o desenho do estado futuro.

Definido o estado atual, foram identificadas, em cada uma das atividades, quais são as perdas no processo, ou seja, quais são as atividades que não agregam valor, visando a eliminação das mesmas.

Considerando o método proposto, é necessário explicitar aqui uma ressalva relacionada à execução da etapa "definir tempos de agregação e não-agregação de valor". No caso em questão, o mapeamento do tempo de agregação e não agregação de valor não foi considerado relevante para o projeto, considerando alta a variabilidade observada nos tempos das atividades. Além disto, o lead time do processo não foi considerado relevante para o cliente em questão. Por este motivo, não foi observado benefício em medir os tempos de cada uma das atividades, e por este motivo esta etapa não foi conduzida. Em outras situações, porém, onde há menor variabilidade nos tempos de execução das atividades, bem como o lead time é relevante, tal mapeamento teria um potencial custo-benefício.

A partir da análise das perdas identificadas, que neste caso não incluiu a observação dos tempos de agregação e não agregação de valor, foi iniciada a modelagem do estado futuro, tanto em nível de processo (VSM) quanto a nível de atividades (EPCs). A Figura 5 apresenta um extrato do estado futuro do processo nomeado Concluir Qualificação, em nível de atividade. A Modelagem do Estado Futuro compreendeu também a mobilização da equipe para que todos visassem o desenho dos processos no estado futuro de modo adequado à melhor maneira de realizar suas atividades. Esta etapa foi crucial para o resultado do projeto, visto que neste ponto foram definidas as melhorias posteriormente implantadas. 
Figura 5 - Processo no estado futuro

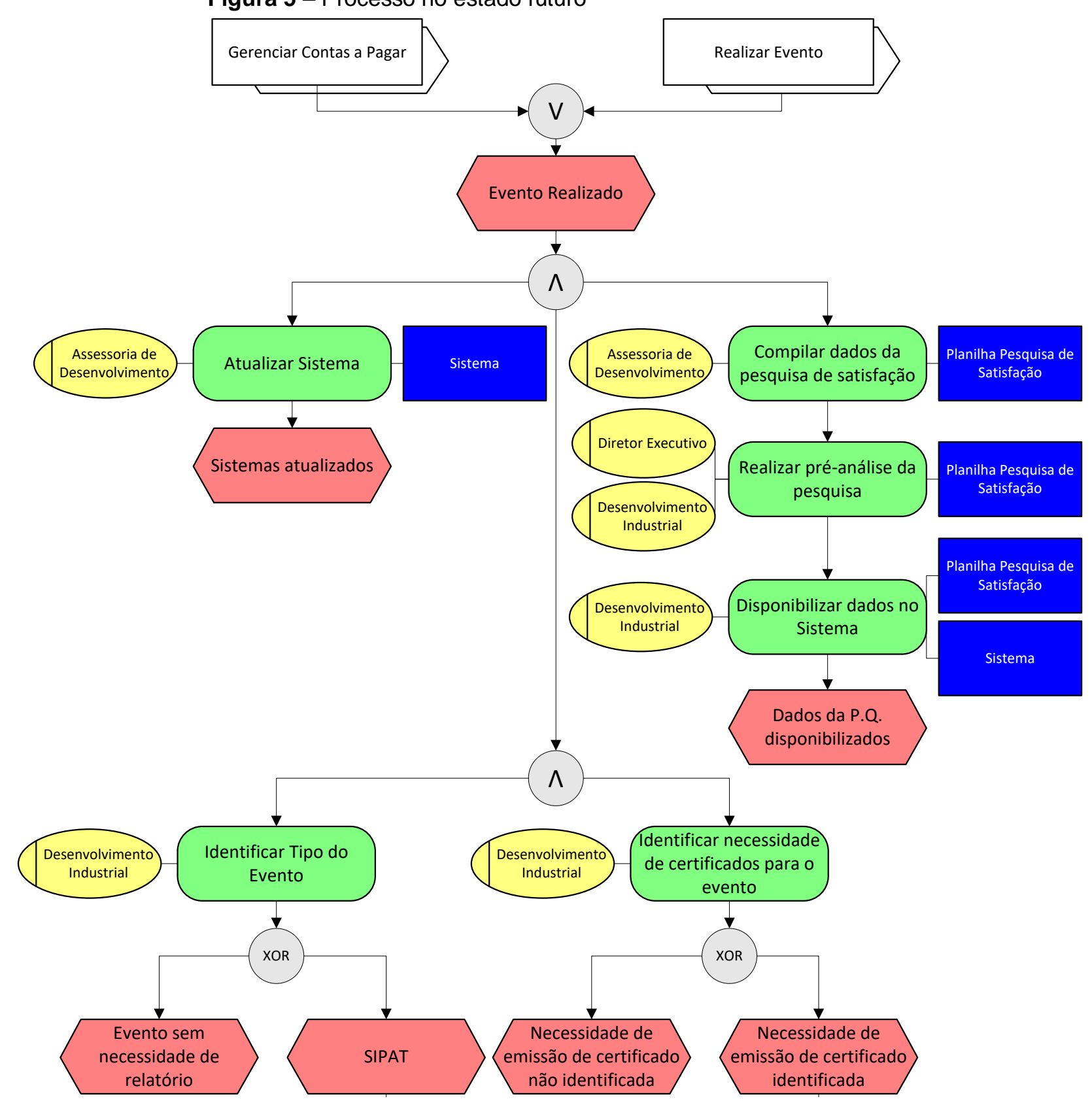

Fonte: Elaborada pelos Autores (2016)

Percorridos todos estes passos, se procurou compreender quais ações seriam realizadas para mudar da situação atual para o projetado, ou seja, quais são os planos de ação para se atingir o objetivo proposto. Após três reuniões entre a equipe consultora, facilitadora, membros e diretoria executiva, foram definidos 18 ações para a redução das perdas no fluxo de valor Qualificação, abrangendo todos os processos analisados, para serem implementados em um prazo de determinado. Os planos foram definidos nos moldes do $5 \mathrm{~W} 2 \mathrm{H}$, expressando: i) porque; ii) onde; iii) o que; iv) quando; v) quem é o responsável e vi) como gerar a mudança. Os itens Onde, Porque, O que e Como foram apresentados no APÊNDICE A deste trabalho, com o objetivo 
de permitir ao leitor o entendimento da natureza das ações realizadas, sendo omitidos as demais colunas do plano de ação.

A última etapa, avaliar os resultados da iniciativa, também deve ser realizada ao fim do prazo de implantação dos planos de ações, para que sejam compreendidos os aspectos positivos e negativos, servindo para tomada de futuras decisões. A seção seguinte implica às considerações finais do trabalho.

\section{CONSIDERAÇÕES FINAIS}

Por observar o desempenho superior que sistemas de produção enxutos apresentam, diversas organizações têm empreendido esforços para utilizar os mesmos conceitos que tornaram a Toyota referência em sistemas produtivos. A efetividade de tais esforços depende da organização e coerência das ações empreendidas em um dado contexto.

Neste sentido, diversos autores trouxeram os conceitos da Manufatura Enxuta para o escritório, aplicando suas ferramentas e relatando resultados positivos. Apesar disto, este trabalho sustentou que a integração entre os conceitos Lean e as ferramentas da Engenharia de Processos de Negócio era frágil.

Por mais que a aplicação de ferramentas Lean em áreas administrativas tenha potencial de melhorar as organizações, não devem ser ignoradas técnicas e conceitos de Gerenciamento de Processos de Negócio consagradas e amplamente utilizadas ao longo do tempo. Este trabalho sustenta que a incorporação de técnicas de Engenharia e Gerenciamento de Processos de Negócio pode ser integrada aos conceitos Lean para a redução de desperdícios em processos administrativos, bem como ferramentas e conceitos Lean podem ser integrados em iniciativas para modelagem, reengenharia e redesenho de processos.

Em síntese, um método que organiza ferramentas e conceitos de ambas as vertentes acadêmicas foi proposto e avaliado. Tal método incorpora as contribuições conceituais da Manufatura Enxuta, enquanto aproveita os métodos para modelagem de processos de negócio estabelecidos, superando as limitações dos métodos até então propostos. A aplicação desta proposta em um projeto funcionou como avaliação e demonstrou a eficácia do método proposto e a possibilidade de aplicação e generalização do mesmo. Com o acompanhamento da execução durante quase um ano, pode-se perceber, além da mudança comportamental das pessoas envolvidas de maneira direta e indireta a partir do entendimento do pensamento lean, o aprimoramento em diversas operações e processos internos que levaram à redução das perdas e tornaram mais ágeis as operações administrativas. Futuros trabalhos devem aplicar o método aqui proposto em diferentes contextos, relatando suas vantagens e desvantagens em determinados contextos e quando comparado à proposição dos demais autores. 


\section{AGRADECIMENTOS}

Os autores agradecem à Direção e Equipe do SINDIMETAL, a qual permitiu e incentivou a publicação do conteúdo exposto neste trabalho. O conhecimento publicado neste artigo não seria gerado sem sua inciativa e esforço em implantar o Lean Office. Desta maneira, os autores reconhecem a contribuição do SINDIMETAL enquanto campo de aplicação e geração de conhecimento, visto que o nível de esforço empregado neste trabalho demonstra seu compromisso com a melhoria contínua e com a filosofia do Lean Manufacturing.

\section{REFERÊNCIAS}

BARBALHO, S.; RICHTER, E. H.; ROZENFELD, H. Melhorando o processo de aquisição de materiais e componentes para protótipos de novos produtos. XXVII Encontro Nacional de Engenharia de Produção. Foz do Iguaçu, 2007.

CARDOSO, G. O. A.; SOUZA, J. P. E. DE; ALVES, J. M. Lean office aplicado em um processo de auditoria de certificação de sistema de gestão da qualidade aeroespacial. XXXII ENcontro Nacional de Engenharia de Produção. Bento Gonçalves, 2012.

DE PAOLI, F. M.; ANDRADE, V. F. D. S.; LUCATO, W. C. O conceito de Lean Office aplicado a um ambiente industrial com produção ETO - Engineer-to-Order. Exacta, v. 12, n. 1,2014

DRESCH, A.; LACERDA, D. P.; ANTUNES, J. A. V. Design science research: método de pesquisa para o avanço da ciência e tecnologia. 1. ed. Porto Alegre: Bookman, 2015.

EXAME. FMI vê queda de 1\% do PIB do Brasil em 2015. Disponível em: <http://exame.abril.com.br/economia/noticias/fmi-ve-queda-de-1-do-pib-do-brasil-em-2015>. Acesso em: 29 abr. 2015.

GREEF, A. C.; FREITAS, M. DO C. D.; ROMANEL, F. B. Lean office: operação, gerenciamento e tecnologias. São Paulo: Atlas, 2012.

LACERDA, D. P. et al. Design Science Research: método de pesquisa para a engenharia de produção. Gestão \& Produção, v. 20, p. 741-761, 2013. http://dx.doi.org/10.1590/S0104530X2013005000014

MAGENHEIMER, K.; REINHART, G.; SCHUTTE, C. S. L. Lean management in indirect business areas: Modeling, analysis, and evaluation of waste. Production Engineering, v. 8, n. 1-2, p. 143-152, 2014. http://dx.doi.org/10.1007/s11740-013-0497-8

OLIVEIRA, J. D. Escritório enxuto (Lean Office). Lean Institute Brasil, n. 2002, p. 1-8, 2007.

ROCHA, A. B. R. B.; WALTER, F. Lean office: um estudo de caso em uma empresa alemã. Fortaleza: XXXV Encontro Nacional de Engenharia de Produção, 2015.

ROOS, C.; SARTORI, S.; PALADINI, E. Uma abordagem do lean office para reduzir e eliminar desperdícios no fluxo de valor de informações e conhecimentos. XXXI Encontro Nacional de Engenharia de Produção, 2011. 
ROTHER, M.; SHOOK, J. Aprendendo a enxergar: mapeando o fluxo de valor para agregar valor e eliminar o desperdício: manual de trabalho de uma ferramenta enxuta. [s.I.] Lean Institute Brasil, 2003.

SERAPHIM, E. C.; SILVA, Í. B. DA; AGOSTINHO, O. L. Lean Office em organizações militares de saúde: estudo de caso do Posto Médico da Guarnição Militar de Campinas. Gestão \& Produção, v. 17, p. 389-405, 2010. http://dx.doi.org/10.1590/S0104$\underline{530 X 2010000200013}$

SHINGO, S. O Sistema Toyota de produção do ponto de vista da engenharia de produção. 2. ed. Porto Alegre: Bookman, 1996.

TAPPING, D.; SHUKER, T. Lean Office: gerenciamento do fluxo de valor para áreas administrativas - 8 passos para planejar, mapear e sustentar melhorias lean nas áreas administrativas. São Paulo: Leopardo Editora, 2010.

TURATI, R. D. C.; MUSETTI, M. A. Aplicação dos conceitos de lean office no setor administrativo público. XXVI Encontro Nacional de Engenharia de Produção, [s.v.], p. 19, 2006.

WOMACK, J. P.; JONES, D. T.; ROOS, D. The machine that changed the world. [s.I.] Simon and Schuster, 1990.

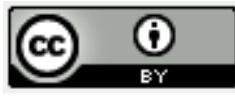

Artigo recebido em 05/01/2016 e aceito para publicação em 10/03/2016 DOI: http://dx.doi.org/10.14488/1676-1901.v16i3.2308 


\section{APÊNDICE A - AÇÕES DE MELHORIA}

Quadro 2 - Plano de Ação

(continua)

\begin{tabular}{|c|c|c|c|c|}
\hline $\mathbf{N}$ & $\begin{array}{c}\text { Onde? } \\
\text { (Processo) }\end{array}$ & O quê? (Mudança) & $\begin{array}{c}\text { Porquê (?) Perdas a } \\
\text { Minimizar }\end{array}$ & Como(?)Ações Necessárias \\
\hline 1 & $\begin{array}{l}\text { Planejar } \\
\text { Agenda Anual } \\
\text { de } \\
\text { Qualificações }\end{array}$ & Estruturar Banco de Sugestões & $\begin{array}{l}\text { Munir o processo de } \\
\text { planejamento com } \\
\text { informações com as } \\
\text { sugestões, devidamente } \\
\text { tratadas. }\end{array}$ & $\begin{array}{l}\text { Banco de Sugestões (compilação de pesquisas e outras } \\
\text { demandas) } \\
\text { - Criar Banco de Sugestões; } \\
\text { - Definir a rotina de tratamento e analise do banco de } \\
\text { sugestões; }\end{array}$ \\
\hline 2 & $\begin{array}{l}\text { Concluir } \\
\text { Processo de } \\
\text { Qualificação }\end{array}$ & $\begin{array}{l}\text { Estruturar alimentação do banco } \\
\text { de sugestões com classificações } \\
\text { depois dos eventos }\end{array}$ & $\begin{array}{l}\text { Sugestões dos } \\
\text { participantes de eventos } \\
\text { são armazenados de } \\
\text { forma que inviabiliza a } \\
\text { sua análise e o uso } \\
\text { desta informação. }\end{array}$ & $\begin{array}{l}\text { - Definir forma de alimentação do banco de sugestões. } \\
\text { - Avaliar forma de alimentação do banco de sugestões junto à } \\
\text { equipe. }\end{array}$ \\
\hline 3 & $\begin{array}{l}\text { Planejar } \\
\text { Agenda Anual } \\
\text { de } \\
\text { Qualificações }\end{array}$ & $\begin{array}{c}\text { Analisar pesquisas de satisfação } \\
\text { (dos eventos e de associados) e } \\
\text { banco de sugestões (mudança no } \\
\text { processo) }\end{array}$ & $\begin{array}{l}\text { Prover subsídios para a } \\
\text { reunião previa com a } \\
\text { diretoria, com o objetivo } \\
\text { de atender as } \\
\text { necessidades das } \\
\text { empresas }\end{array}$ & $\begin{array}{l}\text { - Definir o processo de análise necessário bem como o } \\
\text { resultado da análise; }\end{array}$ \\
\hline
\end{tabular}


Quadro 2 - Plano de Ação

(continuação)

\begin{tabular}{|c|c|c|c|c|}
\hline $\mathbf{N}$ & $\begin{array}{c}\text { Onde? } \\
\text { (Processo) }\end{array}$ & O quê? (Mudança) & $\begin{array}{c}\text { Porquê (?) Perdas a } \\
\text { Minimizar }\end{array}$ & Como(?)Ações Necessárias \\
\hline 4 & $\begin{array}{l}\text { Planejar } \\
\text { Agenda Anual } \\
\text { de } \\
\text { Qualificações }\end{array}$ & $\begin{array}{c}\text { Receber Demandas de } \\
\text { Qualificação com antecipação } \\
\text { (pela Assembleia) }\end{array}$ & $\begin{array}{l}\text { Minimizar o retrabalho } \\
\text { durante os níveis de } \\
\text { aprovação do } \\
\text { planejamento }\end{array}$ & $\begin{array}{l}\text { - Preparar informações para apresentação ao diretor e a } \\
\text { diretoria; } \\
\text { - Reunião prévia com Diretor Executivo para discussão dos } \\
\text { resultados das pesquisas do ano anterior (Setembro); } \\
\text { - Programar sequência das etapas de planejamento do } \\
\text { Sindimetal de maneira a diminuir o possível retrabalho; }\end{array}$ \\
\hline 5 & $\begin{array}{l}\text { Selecionar } \\
\text { Demandas } \\
\text { Qualificação }\end{array}$ & $\begin{array}{l}\text { Definir processo de tratamento de } \\
\text { demandas recebidas fora do ciclo } \\
\text { de planejamento }\end{array}$ & $\begin{array}{l}\text { Reduzir a interferências } \\
\text { no processo; } \\
\text { na programação } \\
\text { orçamentaria e de } \\
\text { agendas; } \\
\text { minimizar risco de } \\
\text { falhas; }\end{array}$ & $\begin{array}{l}\text { - Analisar o processo de recebimento das demandas para } \\
\text { reduzir perdas; } \\
\text { - Encaminhar demandas por meio do banco de sugestões; } \\
\text { - Definir como será o Ciclo de planejamento mais curto para } \\
\text { eventos específicos (ex.: ciclo de } 6 \text { meses para cursos). }\end{array}$ \\
\hline 6 & $\begin{array}{l}\text { Definir } \\
\text { Parceiro } \\
\text { Executor }\end{array}$ & $\begin{array}{l}\text { Cadastro de Palestrantes para } \\
\text { controle da qualidade dos cursos }\end{array}$ & $\begin{array}{l}\text { Minimizar tempo } \\
\text { necessário para procurar } \\
\text { palestrante para um } \\
\text { novo evento; }\end{array}$ & $\begin{array}{l}\text { - Avaliar forma de cadastro que melhora o processo de analise } \\
\text { (decidir: Junto ao cadastro de fornecedores ou as avaliações } \\
\text { (tem que constar o evento no qual o palestrante trabalhou); - } \\
\text { Alterar processo de conclusão da qualificação para que o } \\
\text { cadastro seja atualizado; }\end{array}$ \\
\hline
\end{tabular}


Quadro 2 - Plano de Ação

\begin{tabular}{|c|c|c|c|c|}
\hline $\mathbf{N}$ & $\begin{array}{c}\text { Onde? } \\
\text { (Processo) }\end{array}$ & O quê? (Mudança) & $\begin{array}{c}\text { Porquê (?) Perdas a } \\
\text { Minimizar }\end{array}$ & Como(?)Ações Necessárias \\
\hline 7 & $\begin{array}{l}\text { Definir } \\
\text { Parceiro } \\
\text { Executor }\end{array}$ & $\begin{array}{l}\text { Estabelecer e enviar critérios de } \\
\text { contratação para fornecedores } \\
\text { antes do envio das propostas }\end{array}$ & $\begin{array}{l}\text { Minimizar retrabalho dos } \\
\text { pagamentos fora de } \\
\text { datas padrões }\end{array}$ & $\begin{array}{l}\text { - Criar documento de critérios para os fornecedores; } \\
\text { - Padronizar envio dos critérios para os fornecedores antes da } \\
\text { emissão de propostas; }\end{array}$ \\
\hline 8 & $\begin{array}{l}\text { Definir } \\
\text { Parceiro } \\
\text { Executor }\end{array}$ & $\begin{array}{l}\text { Realizar briefing com palestrante } \\
\text { ou instrutor conforme critérios } \\
\text { definidos }\end{array}$ & $\begin{array}{l}\text { Minimizar probabilidade } \\
\text { de o palestrante ter ruim } \\
\text { performance no evento, } \\
\text { quando isto poderia ser } \\
\text { visto antecipadamente } \\
\text { em um briefing }\end{array}$ & $\begin{array}{l}\text { Formalizar Critérios: Palestra e Curso de Curta Duração } \\
\text { - Palestrante tem muitos tipos de temas, e é necessário alinhar } \\
\text { o objetivo do evento em questão; } \\
\text { - Palestrante é focado no tema, mas é necessário definir qual a } \\
\text { profundidade que se quer no conteúdo; } \\
\text { - O curso / evento está sendo realizado pela primeira vez com } \\
\text { aquele palestrante; } \\
\text { - O palestrante ainda não sabe como funcionam os } \\
\text { procedimentos do evento em questão; }\end{array}$ \\
\hline 9 & $\begin{array}{l}\text { Definir } \\
\text { Parceiro } \\
\text { Executor }\end{array}$ & $\begin{array}{l}\text { Realizar apresentação prévia com } \\
\text { palestrante ou instrutor conforme } \\
\text { critérios definidos }\end{array}$ & $\begin{array}{c}\text { Minimizar probabilidade } \\
\text { de o palestrante ter ruim } \\
\text { performance no evento, } \\
\text { quando isto poderia ser } \\
\text { visto em uma } \\
\text { apresentação previa }\end{array}$ & $\begin{array}{l}\text { Formalizar Critérios: Cursos ou Programas de Longa duração } \\
\text { - Publico com alta interação com o palestrante; } \\
\text { - Conhecimento profundo dos temas discutidos dos } \\
\text { participantes; }\end{array}$ \\
\hline
\end{tabular}


Quadro 2 - Plano de Ação

\begin{tabular}{|c|c|c|c|c|}
\hline $\mathbf{N}$ & $\begin{array}{c}\text { Onde? } \\
\text { (Processo) }\end{array}$ & O quê? (Mudança) & $\begin{array}{c}\text { Porquê (?) Perdas a } \\
\text { Minimizar }\end{array}$ & Como(?)Ações Necessárias \\
\hline 10 & $\begin{array}{l}\text { Divulgar } \\
\text { Evento }\end{array}$ & $\begin{array}{c}\text { Minimizar conflito de informações } \\
\text { entre Agenda de Salas e Agenda } \\
\text { de Atividades }\end{array}$ & $\begin{array}{l}\text { Minimizar o retrabalho e } \\
\text { conflitos quando todas } \\
\text { as agendas não são } \\
\text { atualizadas. Minimizar } \\
\text { retrabalho para inserir } \\
\text { informações em três } \\
\text { locais distintos. }\end{array}$ & $\begin{array}{l}\text { - Testar Alternativas disponíveis: } \\
\text {-- Manter uma única agenda (para todos os eventos e somente o } \\
\text { filtro); } \\
\text {-- Planilha com Agenda de Atividades (a ser alterada) e Agenda } \\
\text { de Salas (apenas visualização); } \\
\text {-- TI: Testar estrutura das Agendas; } \\
\text {-->> Manter atualização das três agendas separadamente; } \\
\text { - Definir melhor alternativa observada; }\end{array}$ \\
\hline 11 & $\begin{array}{l}\text { Divulgar } \\
\text { Evento }\end{array}$ & $\begin{array}{c}\text { Definir informações necessárias } \\
\text { para divulgação em tempo hábil } \\
\text { para divulgação e inscrição das } \\
\text { empresas }\end{array}$ & $\begin{array}{l}\text { Buscar divulgar os } \\
\text { eventos no tempo } \\
\text { adequado } \\
\text { (aproximadamente } 30 \\
\text { dias antes do evento), } \\
\text { reduzir perdas } \\
\text { relacionadas a eventos } \\
\text { não realizados por } \\
\text { divulgação imprópria }\end{array}$ & $\begin{array}{l}\text { Definir tempo necessário para divulgação como } 25 \\
\text { dias;Comunicação e Marketing participar do briefing quando } \\
\text { possível;Sugestões a avaliar: - Criar convite mesmo sem as } \\
\text { informações. Indicar no campo de texto a informação que falta. } \\
\text { Quando a informação chegar, apenas substituir o texto;- Informar } \\
\text { o palestrante no momento da contratação quais informações ele } \\
\text { tem que indicar +- } 30 \text { dias antes do evento, e indicar se ele não } \\
\text { informar isto, a divulgação fica prejudicada; }\end{array}$ \\
\hline 12 & $\begin{array}{l}\text { Divulgar } \\
\text { Evento }\end{array}$ & $\begin{array}{c}\text { Desenvolver Artes para site, } \\
\text { murais e e-mail simultaneamente }\end{array}$ & $\begin{array}{l}\text { Reduzir o retrabalho ao } \\
\text { realizar as artes. }\end{array}$ & - Comunicar TI sobre alteração; \\
\hline
\end{tabular}


Quadro 2 - Plano de Ação

\begin{tabular}{|c|c|c|c|c|}
\hline $\mathbf{N}$ & $\begin{array}{c}\text { Onde? } \\
\text { (Processo) }\end{array}$ & O quê? (Mudança) & $\begin{array}{c}\text { Porquê (?) Perdas a } \\
\text { Minimizar }\end{array}$ & Como(?)Ações Necessárias \\
\hline 13 & $\begin{array}{l}\text { Gerenciar } \\
\text { Inscrições }\end{array}$ & $\begin{array}{l}\text { Encaminhar lista de Inscritos para } \\
\text { cobrança pronta }\end{array}$ & $\begin{array}{l}\text { Reduzir retrabalho ao } \\
\text { redigitar as informações } \\
\text { necessárias }\end{array}$ & $\begin{array}{l}\text { - Criar documento padrão para ser utilizado como modelo para } \\
\text { lista de inscritos para cobrança; }\end{array}$ \\
\hline 14 & $\begin{array}{l}\text { Realizar } \\
\text { Evento }\end{array}$ & $\begin{array}{l}\text { Implantar Checklist para } \\
\text { realização de evento }\end{array}$ & $\begin{array}{c}\text { Melhorar a organização } \\
\text { da infraestrutura } \\
\text { necessária antes e } \\
\text { depois dos eventos } \\
\text { antecipar possíveis } \\
\text { problemas }\end{array}$ & $\begin{array}{l}\text { - Definir o modelo de checklist; } \\
\text { - Realizar reunião com os envolvidos; } \\
\text { - } 30 \text { dias de teste e avaliação após a implantação. }\end{array}$ \\
\hline 15 & $\begin{array}{l}\text { Realizar } \\
\text { Evento }\end{array}$ & $\begin{array}{l}\text { Esclarecer critérios para atuação } \\
\text { da assessoria de imprensa }\end{array}$ & $\begin{array}{l}\text { Padronizar os critérios } \\
\text { para a realização de } \\
\text { cobertura de eventos }\end{array}$ & Definir os critérios para participação da Assessoria \\
\hline 16 & $\begin{array}{l}\text { Realizar } \\
\text { Evento }\end{array}$ & $\begin{array}{l}\text { Uniformizar e padronizar a } \\
\text { aplicação de pesquisa de } \\
\text { satisfação }\end{array}$ & $\begin{array}{l}\text { Formato de informações } \\
\text { incompatíveis para } \\
\text { análise }\end{array}$ & $\begin{array}{l}\text { Identificar e comparar os formulários de pesquisa de satisfação } \\
\text { (inclusive SENAI e SESI); } \\
\text { Avaliar necessidade de uniformizar as pesquisas e impactos } \\
\text { para a análise; }\end{array}$ \\
\hline 17 & $\begin{array}{l}\text { Concluir } \\
\text { Processo de } \\
\text { Qualificação }\end{array}$ & $\begin{array}{l}\text { Uniformizar processo de análise } \\
\text { das pesquisas de satisfação }\end{array}$ & $\begin{array}{c}\text { Informações geradas em } \\
\text { pesquisas de satisfação } \\
\text { podem não ser tratadas } \\
\text { adequadamente por } \\
\text { processos diferentes }\end{array}$ & $\begin{array}{l}\text { - Detalhar os procedimentos realizados no processo de análise } \\
\text { das pesquisas de satisfação (critério: informar anormalidades). } \\
\text { - Consolidar a aplicação do procedimento realizado. }\end{array}$ \\
\hline
\end{tabular}

Fonte: Elaborado pelos Autores (2016) 